PROF. SIRPA LEPPA (Orcid ID : 0000-0002-8265-511X)

Article type : Original Article

\title{
Clinical features and outcome of the patients with sinonasal tract diffuse large B-cell lymphoma in the pre and rituximab eras
}

Pauli Vähämurto, $\mathrm{MD}^{1,2}$, Susanna Mannisto, $\mathrm{MD}, \mathrm{PhD}^{1}$, Marjukka Pollari, $\mathrm{MD}^{1,3}$, Marja-Liisa Karjalainen-Lindsberg, MD, $\mathrm{PhD}^{4}$, Antti A. Mäkitie, MD, Prof ${ }^{2,5}$, Sirpa Leppä, MD, Prof ${ }^{1}$

${ }^{1}$ Department of Oncology, Helsinki University Hospital Comprehensive Cancer Center and Research Program in Applied Tumor Genomics, Faculty of Medicine, University of Helsinki, Helsinki, Finland

${ }^{2}$ Department of Otorhinolaryngology - Head and Neck Surgery, University of Helsinki and Helsinki University Hospital, Research Program in Systems Oncology, Faculty of Medicine, Helsinki, Finland

${ }^{3}$ Department of Oncology, University of Tampere and Tampere University Hospital, Tampere, Finland

${ }^{4}$ Department of Pathology, University of Helsinki and Helsinki University Hospital, Haartman Institute, Helsinki, Finland

${ }^{5}$ Division of Ear, Nose and Throat Diseases, Department of Clinical Sciences, Intervention and Technology, Karolinska Institutet and Karolinska Hospital, Stockholm, Sweden

Running head: Sinonasal tract diffuse large B-cell lymphoma

Correspondence:

Sirpa Leppä, MD, professor

Dept. of Oncology

Helsinki University Hospital Comprehensive Cancer Centre

P.O. Box 180, FI-00029 HUH, Helsinki, Finland

E-mail: sirpa.leppa@helsinki.fi

This article has been accepted for publication and undergone full peer review but has not been through the copyediting, typesetting, pagination and proofreading process, which may lead to differences between this version and the Version of Record. Please cite this article as doi: 10.1111/ejh.13225

This article is protected by copyright. All rights reserved. 


\begin{abstract}
Purpose: Sinonasal tract diffuse large B-cell lymphoma (SNT-DLBCL), a rare extranodal lymphoma, is not well characterized. We performed a population-based study to determine cell of origin, clinical presentation and impact of rituximab (R) and central nervous system (CNS) directed chemotherapy on survival.
\end{abstract}

Patients and methods: Patients with SNT-DLBCL were identified from pathology databases Clinical information was collected and outcomes between different treatment modalities evaluated.

Results: Thirty-two percent of the patients had germinal centre B-cell phenotype. Forty-six patients were treated with curative intent using CHOP (cyclophosphamide, doxorubicin, vincristine, prednisone) or CHOP-like chemotherapy, 21 (46\%) before and 25 (54\%) in the R-era. Additionally, $24(52 \%)$ received CNS-directed chemotherapy. Addition of R to chemotherapy reduced the risk of progression $(\mathrm{RR}=0.368,95 \%$ CI $0.138-0.976, \mathrm{p}=0.045)$ and death $(\mathrm{RR}=0.245,95 \% \mathrm{CI} 0.068-0.883$, $\mathrm{p}=0.032$ ), and translated into better survival (5-y PFS, $67 \%$ vs 38\%, $\mathrm{p}=0.037$; 5 -y OS, $81 \%$ vs $48 \%$, $\mathrm{p}=0.020)$. CNS-directed chemotherapy reduced the risk of progression $(\mathrm{RR}=0.404,95 \% \mathrm{CI} 0.159$ $1.029, \mathrm{p}=0.057)$ and death $(\mathrm{RR}=0.298,95 \% \mathrm{CI} 0.093-0.950, \mathrm{p}=0.041)$, and translated into favorable survival (5-y PFS, 67\% vs 32\%, p=0.050; 5-y OS 82\% vs 43\%, p=0.030).

Conclusion: Patients with SNT-DLBCL benefit from rituximab and CNS-directed chemotherapy.

Keywords: Sinonasal tract, diffuse large B-cell lymphoma, clinical presentation, survival

\title{
Introduction
}

Diffuse large B-cell lymphoma (DLBCL) of the nasal cavity, paranasal sinuses or nasopharynx i.e. sinonasal track (SNT) is a rare lymphoma presentation with an incidence of 0.06-0.17 per 100000 in the western population. However, it is the most common lymphoma in SNT area in the western countries in contrast to the Asian population, where NK/T- and peripheral T-cell lymphomas prevail $[1-4]$.

Previous studies have reported conflicting results on the prognostic impact of SNT involvement in patients with DLBCL [5-8], and varying involvement of different anatomical locations in different publications makes the comparisons difficult. In the rituximab $(\mathrm{R})$ era, the patients with extranodal craniofacial DLBCL seem to have prognosis similar to the patients with primary nodal DLBCL [8]. In the pre-R era, SNT or craniofacial involvement was associated with increased risk of central nervous system (CNS) progression [8]. Kim et al. have reported increased risk of CNS progression in Korean SNT DLBCL patients treated with R-containing immunochemotherapy compared to other DLBCL

This article is protected by copyright. All rights reserved. 
patients [9]. However, in European population SNT or craniofacial involvement as such has not been identified as an independent risk factor for CNS progression in the R era [8].

To date, prospective clinical trials specifically on SNT DLBCL have not been conducted in European population. However, Murawski et al. pooled together 235 craniofacial DLBCL patients (including 93 cases with tumor in paranasal sinuses and 38 in nasal cavity) from 11 consecutive prospective German trials between 2004 and 2012 [8]. Kim et al. reported 74 SNT DLBCL cases among 521 other DLBCL cases in their prospective study on Korean patients treated with R-CHOP (cyclophosphamide, doxorubicin, vincristine, prednisone) [9]. Lee et al. reported 80 Korean SNT DLBCL patients treated with R-CHOP or R-CHOP followed with radiotherapy [10], possibly with partly overlapping study population with the other Korean study [9]. Mian et al. described a retrospective study comparing extranodal head and neck DLBCLs with one another by anatomical location during 1985-2006 [7]. This study included 53 DLBCLs of the nasal cavity and paranasal sinuses among other head and neck (HN) lymphomas. Total number of patients was 488 , and only seven patients were treated with immunochemotherapy [7]. A register-study described tumor location and use of radiotherapy for 852 SNT DLBCL cases but information on chemotherapy was not provided [1].

Together, the above referred studies have demonstrated that the addition of $\mathrm{R}$ to chemotherapy has improved the outcome of patients with SNT DLBCL, as has been seen in patients with primary nodal DLBCL $[8,11]$. The addition of $\mathrm{R}$ has also reduced the rate of CNS progression in extralymphatic craniofacial DLBCL, and specifically in paranasal DLBCL [8]. In some studies, intrathecally (it) given CNS prophylaxis has also been associated with better survival and lower risk of CNS progression in DLBCL in general, likewise in SNT lymphomas [6, 12, 13], but a clear survival benefit has not been seen in all studies, including extralymphatic craniofacial DLBCL reported by Murawski et al. [8, 14]. In clinical practice, it methotrexate (MTX), intravenously (iv) administered CNSdirected high dose (HD)-MTX or HD-cytarabine are often combined with immunochemotherapy in patients with SNT DLBCL.

Based on gene expression profiling (GEP), DLBCL is molecularly divided according to cell-of-origin (COO) into germinal center B-cell (GCB), activated B-cell (ABC) type and unclassified subtypes [15, 16]. As GEP is not yet feasible in routine clinical practice, immunohistochemical algorithms, such as the Hans algorithm dividing DLBCL into GCB and non-GCB immunophenotypes, have been developed and incorporated into diagnostics [17]. However, information on the molecular subtype of SNT DLBCL has so far been limited. Lee et al. described 80 nasal cavity and paranasal DLBCL patients, and found $12.5 \%$ of them to be GCB, $58.7 \%$ non-GCB and $28.8 \%$ unknown immunophenotypes [10]. In the DLBCL occurring in the Waldeyer's ring, GCB immunophenotype has been reported to account for $57-75 \%$ of the cases, and to correlate with superior survival [18-20].

This article is protected by copyright. All rights reserved. 
In an analysis of immunochemotherapy-treated HN DLBCL patients, including nine SNT cases (including also larynx tumors), $68 \%$ of the extranodal HN DLBCL patients had GCB immunophenotype, but SNT DLBCL was not studied separately [21], the COO did not have an impact on survival [21]. In a Japanese study on 29 SNT DLBCL patients treated between 2002 and $2013,82 \%$ of the patients had non-GCB immunophenotype, which correlated with inferior survival [22]. BCL2 expression has been observed in 55\% of the Waldeyer's ring DLBCL patients, and found to associate with adverse survival in the pre R era, the effect, however, overcome by COO distinction [18].

We have previously reported a series of patients diagnosed with SNT lymphoid malignancies in Southern Finland [3]. The aim of this population-based study was to describe clinical characteristics and outcome of the patients with SNT DLBCL treated in Southern Finland. In addition, we wanted to characterize $\mathrm{COO}$ as well as prevalence of three potential prognostic factors, i.e. expression of BCL2, BCL6, and MYC.

\section{Materials and Methods}

The hospital records of SNT DLBCL patients treated at the Helsinki and Tampere University Hospitals were retrospectively reviewed on parameters for patient demographics, tumor location and characteristics, treatment and outcome. Follow-up data were collected up to 60 months. Pathology reports were reviewed, diagnostic tissue blocks acquired from the pathology archives, and a tissue microarray (TMA) block constructed and $5 \mu \mathrm{m}$ sections used for the immunohistochemistry.

TMA was subjected to standard diagnostic immunohistochemistry using antibodies against CD79, CD10, BCL2, BCL6, MUM1 and MYC. The diagnosis was then reviewed according to the current WHO classification [23] and COO defined according to clinical standards and the Hans algorithm by expert hematopathologist (M-L K-L) [17].

The $\mathrm{X}^{2}$ test was used to assess the differences in the frequency of the baseline characteristics and treatment modalities. Cox univariate regression analyses were performed to study the prognostic value of the baseline and treatment related factors. Kaplan-Meier method was used to estimate survival rates. The differences in the rates were compared with log-rank test.

Overall survival (OS) was defined from the date of diagnosis until last follow up or death from any cause. Progression free survival (PFS) was measured from the date of diagnosis until relapse, progression or death from any cause. Subjects were censored on their last follow up visits. Probability values $\leq 0.05$ were considered statistically significant. All p-values were two-tailed.

SPSS Statistics (IBM Corp. Released 2013. IBM SPSS Statistics for Windows, Armonk, NY: IBM

This article is protected by copyright. All rights reserved. 
Corp.) was used for all statistical analyses.

The study and sampling were approved by the Institutional Review Boards, Ethics Committees and Finnish National Supervisory Authority for Welfare and Health.

\section{Results}

\section{Patient demographics and treatment modalities}

Sixty-three patients with SNT DLBCL diagnosed between 1977 and 2015 were identified. Of them, 46 patients were treated with curative intent using CHOP or CHOP-like therapy, 21 (46\%) before and $25(54 \%)$ in the rituximab era. In addition, 24 (52\%) patients received CNS-directed (CNS dir) chemotherapy, iv or it MTX, iv or it cytarabine, or both iv and it chemotherapy in combination. Radiotherapy was given to 18 (39\%) patients.

The median age for patients treated with curative intent was 64 (range, 26-84) years at diagnose. Majority of the patients (65\%) were males, had good performance status (89\%), limited stage disease (74\%) according to Ann Arbor staging criteria and low International Prognostic Index (IPI, 76\%). Patient demographics are summarized in Table 1 and treatment modalities listed in Table 2.

Baseline characteristics were equally distributed between the R+ and R-groups. However, the patients in the CNS dir+ group were younger than the ones in the CNS dir- group ( $<60$ years, $67 \%$ vs $27 \%$, $\mathrm{p}=0.010$ ). Otherwise, no significant differences on the baseline characteristics were found. CNSdirected chemotherapy was used equally often in the $\mathrm{R}+$ and $\mathrm{R}$ - groups, whereas radiotherapy was more commonly given in the $\mathrm{R}$ - than $\mathrm{R}+$ group ( $62 \%$ vs $39 \%$, $\mathrm{p}=0.003)$.

The most common location of DLBCL was nasopharynx (52\%). Nasal cavity was affected in 39\% and paranasal cavities in $34 \%$ of the patients. Patients having a tumor reaching several SNT locations were counted to each location the tumor reached and therefore, the total percentage exceeds $100 \%$.

Nasopharyngeal or nasal cavity location were not associated with known clinical risk factors, and they were equally distributed in different treatment groups (R or CNS dir). Paranasal cavity location was not associated with any known risk factors either, but the patients with tumor in the paranasal cavities received more often CNS-directed chemotherapy ( $80 \%$ vs $35 \%$, $\mathrm{p}=0.010)$.

Adequate tumor sample or contemporary pathology report was available for 47 cases. Among all SNT cases $32 \%$ of the patients had GCB immunophenotype, whereas in paranasal cavities, the proportion of GCB-cases was $47 \%$. The patients with GCB immunophenotype were younger than the patients with the non-GCB immunophenotype ( $<60$ years old; $63 \%$ vs. $28 \%$; $p=0.029$ ). MYC positive cases

This article is protected by copyright. All rights reserved. 
had more often high LD (57\%) than MYC negative cases (none, $\mathrm{p}=0.017)$. BCL2 negative cases had more often high LD (80\%) than BCL2 positive cases $(32 \%, \mathrm{p}=0.040)$ and BCL2 negative cases got more often CNS-directed chemotherapy ( $83 \%)$ than BCL2 positive cases $(40 \%, \mathrm{p}=0.045)$. Double expressor (DE) lymphomas had more often high LD (57\%) than non-DE lymphomas (none, $\mathrm{p}=0.017$ ). In addition, proportion of DE lymphomas (63\%) was higher than the $17-29 \%$ described in DLBCL in general [25-28]. Results from immunohistochemistry are summarized in Table 3.

\section{Outcome}

Among the 46 patients treated with CHOP-like chemotherapy, 19 patients relapsed and 14 patients died from lymphoma during the follow-up time of 60 months (median follow-up time 47 months; range, 4-60 months) resulting in 5 years (5-y) PFS and OS rates of $51 \%$ and $63 \%$, respectively. Only one CNS progression was recorded. In Cox-regression analyses, neither the known clinical risk factors (Eastern Cooperative Oncology Group (ECOG) performance status, age over 60 years, Ann Arbor Stage, high LDH, more than one extranodal location, or IPI) nor the location of SNT tumor correlated with survival (data not shown).

More aggressive chemotherapies, including for example Magrath, M-BACOD, M-BAIOD, and DAEPOCH-R regimens $(n=11)$ were not superior to $\mathrm{CHOP} / \mathrm{CNOP} / \mathrm{COP}$ combination therapies $(\mathrm{n}=35)$. However, addition of $\mathrm{R}$ to chemotherapy $(\mathrm{R}+)$ reduced the risk of progression $(\mathrm{RR}=0.368,95 \% \mathrm{CI}$ $0.138-0.976, \mathrm{p}=0.045)$ and death $(\mathrm{RR}=0.245,95 \% \mathrm{CI} 0.068-0.883, \mathrm{p}=0.032)$, and translated into better survival in comparison to the patients treated in the pre-rituximab era (R-group; 5-y PFS 67\% vs $38 \%$, p $=0.037$; 5 -y OS $81 \%$ vs $48 \%$, p=0.020; Figure $1 \mathrm{a}$-b). Likewise, CNS-directed chemotherapy (CNS dir + ) reduced the risk of progression (RR 0.404, 95\% CI 0.159-1.029, $\mathrm{p}=0.057$ ) and death $(\mathrm{RR}=0.298,95 \% \mathrm{CI} 0.093-0.950, \mathrm{p}=0.041)$, and translated into favorable survival in comparison to the patients not receiving CNS-directed chemotherapy (CNS dir-group; 5-y PFS, 67\% vs $32 \%, p=0.050 ; 5$-y OS $82 \%$ vs $43 \%$, $p=0.030$; Figure 2 a-b).

Altogether, the patients treated with both immunochemotherapy $(\mathrm{R}+)$ and CNS-directed chemotherapy had superior outcome (5-y PFS, 74\%; 5-y OS 100\%) in comparison to the patients in the R+ CNS dir-, R- CNS dir+ and R- CNS dir- groups (for R+ CNS dir- group 5-y PFS 61\% and 5-y OS 60\%; for R-CNS dir+ group 5-y PFS, 55\% and 5-y OS 64\%; for R-CNS dir- group; 5-y PFS 20\% and 5 -y OS $30 \%$, PFS $\mathrm{p}=0.037$ and OS $\mathrm{p}=0.015$; Figure 3).

This article is protected by copyright. All rights reserved. 


\section{Patient demographics and outcome among patients less than 76 years}

In our study population, the oldest patients were not treated with CNS-directed chemotherapy. To acquire better estimate of the impact of CNS-directed chemotherapy on the outcome, we selected a subgroup of patients less than 76 years treated with CHOP or CHOP-like chemotherapy, and repeated the analyses. Patient demographics of this subgroup are shown in Table 1. The median age at diagnosis was 58 years (range, 26-75). In this cohort, 20 (50\%) patients were treated before and 20 $(50 \%)$ in the rituximab era. In addition, $24(60 \%)$ patients received CNS-directed chemotherapy. Patient demographics were equally distributed between R+ vs R-, and CNS dir+ vs CNS dirsubgroups. Additional CNS-directed chemotherapy was also given equally often in R+ and Rsubgroups.

As in the total study cohort, the addition of rituximab to chemotherapy reduced the risk of progression (PFS RR $=0.250,95 \%$ CI 0.09-0.888, $\mathrm{p}=0.033)$ and death $(\mathrm{OS} R \mathrm{RR}=0.116,95 \%$ CI 0.015-0.917, $\mathrm{p}=0.041$ ) and resulted in better survival in comparison to the patients treated in the pre-rituximab era (5-y PFS 74\% vs 40\%, p=0.021; 5-y OS 94\% vs 50\%, p=0.013; Figure $1 \mathrm{c}-\mathrm{d}$ ). Additional CNSdirected chemotherapy also reduced the risk of progression (PFS RR $=0.432,95 \%$ CI 0.156-1.194, $\mathrm{p}=0.105)$ and death $(\mathrm{OS} \mathrm{RR}=0.29795 \%$ CI 0.087-1.016, $\mathrm{p}=0.053)$ and translated into favorable survival in comparison to the patients not receiving CNS-directed chemotherapy (5-y PFS, 67\% vs $34 \%, p=0.096 ; 5$-y OS $82 \%$ vs $42 \%, p=0.040$; Figure 2 c-d).

\section{Discussion}

We report a population-based series of SNT DLBCL, a rare extranodal lymphoma, with comprehensive clinical data, including anatomical distribution, clinicopathological presentation and survival during pre-R and $\mathrm{R}$ eras. In our cohort, majority of the patients were males, had limited stage, good performance status and low IPI score. The most common location of the lymphoma was nasopharynx. PFS and OS rates were comparable with previous data $[1,7,8,10]$, and did not differ in various anatomic sublocations. Unexpectedly, the rate of CNS progression was relatively low (overall 2.2\%).

We performed a pathology review according to revised WHO classification and determined the molecular subtype of the SNT DLBCL cases immunohistochemically using Hans algorithm [17, 23]. Accordingly, the GCB phenotype was found to be almost as common in paranasal location as the nonGCB phenotype, whereas the non-GCB cases prevailed among all SNT cases. The findings illustrate

This article is protected by copyright. All rights reserved. 
that SNT DLBCL is immunophenotypically different from DLBCL in the Waldeyer's ring, where the GCB phenotype is more frequent [18-20]. Previous analysis on Korean and Japanese population also showed that non-GCB phenotype is more common in the nasal cavity and paranasal sinuses, or in the SNT area than the reported share in the Waldeyer's ring [10,22]. Our results thus verify those findings in the European population. We further observed that potential prognostic factors, BCL2 and BCL6 were frequently positive and rather evenly in all locations. MUM1 positivity was more common among the patients with lymphomas in the nasal cavity and the nasopharynx than among the patients with paranasal involvement. Data on MYC expression was available for too few patients to make any conclusions (Table 3). As expected, GCB expression profile was linked to decreased risk of progression and BCL2 positivity higher risk of progression, but significance of these findings have to be validated in a larger cohort. Surprisingly, BCL6 positive cases had lower risk of progression than negative cases, but since this result was non-significant as well, it has to be studied further in a larger patient cohort.

In our study cohort, addition of rituximab to CHOP-like chemotherapy reduced the risk of progression and death in comparison to the patients treated in the pre- $\mathrm{R}$ era. The finding is consistent with previous results on DLBCL patients in general [11, 29-32], as well as with the data on patients with extranodal craniofacial DLBCL [8], although the survival benefit of the immunochemotherapy among the patients with extranodal craniofacial DLBCL in the last mentioned study by Murawski et al. was not significant.

Schmitz et al. clarified the role of extranodal location along with other potential risk factors to estimate the risk of CNS progression and observed that SNT location was not associated with increased risk of CNS progression [33]. To our knowledge, however, previous results have not shown that CNS-directed chemotherapy would not benefit the patients with the SNT DLBCL. In our cohort, only one CNS progression was recorded, and therefore the impact of different treatment modalities on the risk of CNS progression could not be evaluated. However, an important finding in our study was that the use of CNS-directed chemotherapy reduced the rate of systemic relapses and deaths and translated into better PFS and OS. The best outcome was seen among the patients treated with both R and CNS-directed chemotherapy. In the lack of prospective trials, our results support the use of CNSdirected chemotherapy as a part of the immunochemoterapy to enhance systemic disease control.

In our study cohort, patients 76 years of age or older did not receive CNS-directed chemotherapy. In order to balance the distribution of different treatment modalities, we performed a subanalysis with the patients less than 76 years of age. In this subgroup, the age was equally distributed between the patients in CNS dir+ and CNS dir- subgroups, and the survival results were similar to the findings seen in the total patient population. Thus, we suggest eligible elderly patients, at least up to 76 years of age, to be treated with additional CNS-directed chemotherapy.

This article is protected by copyright. All rights reserved. 
The strengths of our study are a relatively large and comprehensive collection of clinical data and some molecular information on a rare extranodal lymphoid malignancy from two treatment eras. As a limitation inherent to retrospective analyses and long inclusion period, a potential patient selection bias must be considered when interpreting the present findings. Nevertheless our study demonstrates a favorable survival in SNT DLBCL patients treated with immunochemotherapy. Importantly, the survival of these patients can be improved even further by adding CNS-directed chemotherapy to the immunochemotherapy backbone, warranting their validation in prospective clinical trials.

\section{Acknowledgments}

This work was supported by grants from the Academy of Finland (to S.L.), Finnish Cancer Foundation (to S.L.), Sigrid Juselius Foundation (to S.L.), University of Helsinki (to S.L. \& P.V.), Helsinki University Hospital (to S.L. \& S.M) Finska Läkaresällskapet (to P.V.), Perklen Foundation (to P.V.), The Finnish ORL-HNS Foundation (P.V.) and Finnish Oncology Association (to M.P. \& P.V.).

\section{References}

[1] V.V. Kanumuri, M.N. Khan, A. Vazquez, S. Govindaraj, S. Baredes and J.A. Eloy, Diffuse Large B-Cell Lymphoma of the Sinonasal Tract: Analysis of Survival in 852 Cases, Am.J.Otolaryngol. 35 (2014), pp. 154-158.

[2] P.M. Dubal, R. Dutta, A. Vazquez, T.D. Patel, S. Baredes and J.A. Eloy, A Comparative Population-Based Analysis of Sinonasal Diffuse Large B-Cell and Extranodal NK/T-Cell Lymphomas, Laryngoscope. 125 (2015), pp. 1077-1083.

[3] P. Vahamurto, K. Silventoinen, S.I. Vento, M.L. Karjalainen-Lindsberg, A. Haapaniemi, L. Back, S. Mannisto, S. Leppa and A.A. Makitie, Clinical Findings of Extranodal SNT Lymphoid Malignancies in a Four-Decade Single-Centre Series, Eur.Arch.Otorhinolaryngol. (2016).

[4] T.T. Yen, R.C. Wang, R.S. Jiang, S.C. Chen, S.H. Wu and K.L. Liang, The Diagnosis of Sinonasal Lymphoma: A Challenge for Rhinologists., Eur.Arch.Otorhinolaryngol. 269 (2012), pp. 1463-1469.

[5] J. Hausdorff, E. Davis, G. Long, R. Hoppe, M. van der Pas, C. Lassman, O. Kamel and C. Jacobs, Non-Hodgkin's Lymphoma of the Paranasal Sinuses: Clinical and Pathological Features, and Response to Combined-Modality Therapy, Cancer J.Sci.Am. 3 (1997), pp. 303-311.

This article is protected by copyright. All rights reserved. 
[6] J.J. Laskin, K.J. Savage, N. Voss, R.D. Gascoyne and J.M. Connors, Primary Paranasal Sinus Lymphoma: Natural History and Improved Outcome with Central Nervous System Chemoprophylaxis, Leuk.Lymphoma. 46 (2005), pp. 1721-1727.

[7] M. Mian, D. Capello, M.B. Ventre, D. Grazio, M. Svaldi, A. Rossi, R. Tsang, M.K. Gospodarowicz, E. Oldani, M. Federico, S. Luminari, L. Marcheselli, E.M. Pogliani, F. Rossini, M.E. Cabrera, M. Martelli, G. Gutierrez-Garcia, M. Busetto, C. Visco, M. Fiegl, D. Rossi, G. Gaidano, F. Cavalli, E. Zucca, A. Rambaldi, S. Cortelazzo and on behalf of the International Extranodal Lymphoma Study Group (IELSG), Early-Stage Diffuse Large B Cell Lymphoma of the Head and Neck: Clinico-Biological Characterization and 18 Year Follow-Up of 488 Patients (IELSG 23 Study), Ann.Hematol. (2013).

[8] N. Murawski, G. Held, M. Ziepert, B. Kempf, A. Viardot, M. Hanel, M. Witzens-Harig, R. Mahlberg, C. Rube, J. Fleckenstein, C. Zwick, B. Glass, N. Schmitz, S. Zeynalova and M. Pfreundschuh, The Role of Radiotherapy and Intrathecal CNS Prophylaxis in Extralymphatic Craniofacial Aggressive B-Cell Lymphomas, Blood. 124 (2014), pp. 720-728.

[9] S.J. Kim, J.S. Hong, M.H. Chang, J.A. Kim, J.Y. Kwak, J.S. Kim, D.H. Yoon, W.S. Lee, Y.R. Do, H.J. Kang, H.S. Eom, Y. Park, J.H. Won, Y.C. Mun, H.J. Kim, J.H. Kwon, J.H. Kong, S.Y. Oh, S. Lee, S.H. Bae, D.H. Yang, H.J. Jun, Y.S. Kim, H.J. Yun, S.I. Lee, M.K. Kim, E.K. Park, W.S. Kim and C. Suh, Highly Elevated Serum Lactate Dehydrogenase is Associated with Central Nervous System Relapse in Patients with Diffuse Large B-Cell Lymphoma: Results of a Multicenter Prospective Cohort Study, Oncotarget (2016).

[10] G.W. Lee, S.I. Go, S.H. Kim, J. Hong, Y.R. Kim, S. Oh, S.Y. Kim, Y.R. Do, H. Lee, S.I. Lee, S.H. Bae, S.Y. Oh, M.K. Song, W.S. Lee, B. Lee, J.S. Kim, M.K. Kim, H.J. Kang, J.S. Ahn, H.Y. Yhim, H.J. Kim, S.J. Kim, W.S. Kim, C. Suh and Consortium for Improving Survival of Lymphoma (CISL) study group, Clinical Outcome and Prognosis of Patients with Primary Sinonasal Tract Diffuse Large B-Cell Lymphoma Treated with Rituximab-Cyclophosphamide, Doxorubicin, Vincristine and Prednisone Chemotherapy: A Study by the Consortium for Improving Survival of Lymphoma, Leuk.Lymphoma. 56 (2015), pp. 1020-1026.

[11] B. Coiffier, C. Thieblemont, E. Van Den Neste, G. Lepeu, I. Plantier, S. Castaigne, S. Lefort, G. Marit, M. Macro, C. Sebban, K. Belhadj, D. Bordessoule, C. Ferme and H. Tilly, Long-Term Outcome of Patients in the LNH-98.5 Trial, the First Randomized Study Comparing Rituximab-CHOP to Standard CHOP Chemotherapy in DLBCL Patients: A Study by the Groupe d'Etudes Des Lymphomes De l'Adulte, Blood. 116 (2010), pp. 2040-2045.

[12] H.T. Arkenau, G. Chong, D. Cunningham, D. Watkins, R. Agarwal, B. Sirohi, M. Trumper, A. Norman, A. Wotherspoon and A. Horwich, The Role of Intrathecal Chemotherapy Prophylaxis in Patients with Diffuse Large B-Cell Lymphoma, Ann.Oncol. 18 (2007), pp. 541-545.

[13] E. Zucca, A. Conconi, T.I. Mughal, A.H. Sarris, J.F. Seymour, U. Vitolo, R. Klasa, M. Ozsahin, G.M. Mead, M.A. Gianni, S. Cortelazzo, A.J. Ferreri, A. Ambrosetti, M. Martelli, C.

This article is protected by copyright. All rights reserved. 
Thieblemont, H.G. Moreno, G. Pinotti, G. Martinelli, R. Mozzana, S. Grisanti, M. Provencio, M. Balzarotti, F. Laveder, G. Oltean, V. Callea, P. Roy, F. Cavalli, M.K. Gospodarowicz and International Extranodal Lymphoma Study Group, Patterns of Outcome and Prognostic Factors in Primary Large-Cell Lymphoma of the Testis in a Survey by the International Extranodal Lymphoma Study Group, J.Clin.Oncol. 21 (2003), pp. 20-27.

[14] V. Boehme, N. Schmitz, S. Zeynalova, M. Loeffler and M. Pfreundschuh, CNS Events in Elderly Patients with Aggressive Lymphoma Treated with Modern Chemotherapy (CHOP-14) with Or without Rituximab: An Analysis of Patients Treated in the RICOVER-60 Trial of the German High-Grade Non-Hodgkin Lymphoma Study Group (DSHNHL), Blood. 113 (2009), pp. 38963902 .

[15] G. Lenz, G. Wright, S.S. Dave, W. Xiao, J. Powell, H. Zhao, W. Xu, B. Tan, N. Goldschmidt, J. Iqbal, J. Vose, M. Bast, K. Fu, D.D. Weisenburger, T.C. Greiner, J.O. Armitage, A. Kyle, L. May, R.D. Gascoyne, J.M. Connors, G. Troen, H. Holte, S. Kvaloy, D. Dierickx, G. Verhoef, J. Delabie, E.B. Smeland, P. Jares, A. Martinez, A. Lopez-Guillermo, E. Montserrat, E. Campo, R.M. Braziel, T.P. Miller, L.M. Rimsza, J.R. Cook, B. Pohlman, J. Sweetenham, R.R. Tubbs, R.I. Fisher, E. Hartmann, A. Rosenwald, G. Ott, H.K. Muller-Hermelink, D. Wrench, T.A. Lister, E.S. Jaffe, W.H. Wilson, W.C. Chan, L.M. Staudt and Lymphoma/Leukemia Molecular Profiling Project, Stromal Gene Signatures in Large-B-Cell Lymphomas, N.Eng1.J.Med. 359 (2008), pp. 2313-2323.

[16] A. Rosenwald, G. Wright, W.C. Chan, J.M. Connors, E. Campo, R.I. Fisher, R.D. Gascoyne, H.K. Muller-Hermelink, E.B. Smeland, J.M. Giltnane, E.M. Hurt, H. Zhao, L. Averett, L. Yang, W.H. Wilson, E.S. Jaffe, R. Simon, R.D. Klausner, J. Powell, P.L. Duffey, D.L. Longo, T.C. Greiner, D.D. Weisenburger, W.G. Sanger, B.J. Dave, J.C. Lynch, J. Vose, J.O. Armitage, E. Montserrat, A. Lopez-Guillermo, T.M. Grogan, T.P. Miller, M. LeBlanc, G. Ott, S. Kvaloy, J. Delabie, H. Holte, P. Krajci, T. Stokke, L.M. Staudt and Lymphoma/Leukemia Molecular Profiling Project, The use of Molecular Profiling to Predict Survival After Chemotherapy for Diffuse Large-B-Cell Lymphoma, N.Engl.J.Med. 346 (2002), pp. 1937-1947.

[17] C.P. Hans, D.D. Weisenburger, T.C. Greiner, R.D. Gascoyne, J. Delabie, G. Ott, H.K. MullerHermelink, E. Campo, R.M. Braziel, E.S. Jaffe, Z. Pan, P. Farinha, L.M. Smith, B. Falini, A.H. Banham, A. Rosenwald, L.M. Staudt, J.M. Connors, J.O. Armitage and W.C. Chan, Confirmation of the Molecular Classification of Diffuse Large B-Cell Lymphoma by Immunohistochemistry using a Tissue Microarray, Blood. 103 (2004), pp. 275-282.

[18] L. de Leval, C. Bonnet, C. Copie-Bergman, L. Seidel, M. Baia, J. Briere, T.J. Molina, B. Fabiani, T. Petrella, J. Bosq, C. Gisselbrecht, R. Siebert, H. Tilly, C. Haioun, G. Fillet and P. Gaulard, Diffuse Large B-Cell Lymphoma of Waldeyer's Ring has Distinct Clinicopathologic Features: A GELA Study, Ann.Oncol. 23 (2012), pp. 3143-3151.

This article is protected by copyright. All rights reserved. 
[19] A. Lopez-Guillermo, L. Colomo, M. Jimenez, F. Bosch, N. Villamor, L. Arenillas, A. Muntanola, S. Montoto, E. Gine, D. Colomer, S. Bea, E. Campo and E. Montserrat, Diffuse Large B-Cell Lymphoma: Clinical and Biological Characterization and Outcome According to the Nodal Or Extranodal Primary Origin, J.Clin.Oncol. 23 (2005), pp. 2797-2804.

[20] C. Wang, W. Li, C. Liu, H. He and O. Bai, Analysis of Clinical and Immunophenotypic Features Along with Treatment Outcomes of Diffuse Large B Cell Lymphoma Patients, Based on the Involvement of Nodal Or Extranodal Primary Sites, Blood Cells Mol.Dis. 57 (2016), pp. 42-49.

[21] L.A. Sanchez, A.M. Redondo, O.B. Munez, E. Sebastian, M. Alcoceba, M. Gonzalez, A. Martin and D. Caballero, Extranodal and Nodal Diffuse Large B Cell Lymphoma of the Head and Neck: Two Different Entities?, Ann.Hematol. 94 (2015), pp. 609-616.

[22] J. Carreras, Y.Y. Kikuti, S. Bea, M. Miyaoka, S. Hiraiwa, H. Ikoma, R. Nagao, S. Tomita, D. Martin-Garcia, I. Salaverria, A. Sato, A. Ichiki, G. Roncador, J.F. Garcia, K. Ando, E. Campo and N. Nakamura, Clinicopathological Characteristics and Genomic Profile of Primary Sinonasal Tract Diffuse Large B Cell Lymphoma (DLBCL) Reveals Gain at 1q31 and RGS1 Encoding Protein; High RGS1 Immunohistochemical Expression Associates with Poor overall Survival in DLBCL Not Otherwise Specified (NOS), Histopathology. 70 (2017), pp. 595-621.

[23] S. Swerdlow, E. Campo, N. Harris, E. Jaffe, S. Pileri, H. Stein and J. Thiele (eds.), WHO Classification of Tumours of Haematopoietic and Lymphoid Tissues, Revised 4th Edition, Volume 2 ed., , WHO, 2017.

[24] I. Magrath, M. Adde, A. Shad, D. Venzon, N. Seibel, J. Gootenberg, J. Neely, C. Arndt, M. Nieder, E. Jaffe, R.A. Wittes and I.D. Horak, Adults and Children with Small Non-CleavedCell Lymphoma have a Similar Excellent Outcome when Treated with the Same Chemotherapy Regimen, J.Clin.Oncol. 14 (1996), pp. 925-934.

[25] T.M. Green, K.H. Young, C. Visco, Z.Y. Xu-Monette, A. Orazi, R.S. Go, O. Nielsen, O.V. Gadeberg, T. Mourits-Andersen, M. Frederiksen, L.M. Pedersen and M.B. Moller, Immunohistochemical Double-Hit Score is a Strong Predictor of Outcome in Patients with Diffuse Large B-Cell Lymphoma Treated with Rituximab Plus Cyclophosphamide, Doxorubicin, Vincristine, and Prednisone, J.Clin.Oncol. 30 (2012), pp. 3460-3467.

[26] T.J. Molina, D. Canioni, C. Copie-Bergman, C. Recher, J. Briere, C. Haioun, F. Berger, C. Ferme, M.C. Copin, O. Casasnovas, C. Thieblemont, T. Petrella, K. Leroy, G. Salles, B. Fabiani, F. Morschauser, N. Mounier, B. Coiffier, F. Jardin, P. Gaulard, J.P. Jais and H. Tilly, Young Patients with Non-Germinal Center B-Cell-Like Diffuse Large B-Cell Lymphoma Benefit from Intensified Chemotherapy with ACVBP Plus Rituximab Compared with CHOP Plus Rituximab: Analysis of Data from the Groupe d'Etudes Des Lymphomes De l'Adulte/lymphoma Study Association Phase III Trial LNH 03-2B, J.Clin.Oncol. 32 (2014), pp. 3996-4003.

This article is protected by copyright. All rights reserved. 
[27] N.A. Johnson, G.W. Slack, K.J. Savage, J.M. Connors, S. Ben-Neriah, S. Rogic, D.W. Scott, K.L. Tan, C. Steidl, L.H. Sehn, W.C. Chan, J. Iqbal, P.N. Meyer, G. Lenz, G. Wright, L.M. Rimsza, C. Valentino, P. Brunhoeber, T.M. Grogan, R.M. Braziel, J.R. Cook, R.R. Tubbs, D.D. Weisenburger, E. Campo, A. Rosenwald, G. Ott, J. Delabie, C. Holcroft, E.S. Jaffe, L.M. Staudt and R.D. Gascoyne, Concurrent Expression of MYC and BCL2 in Diffuse Large B-Cell Lymphoma Treated with Rituximab Plus Cyclophosphamide, Doxorubicin, Vincristine, and Prednisone, J.Clin.Oncol. 30 (2012), pp. 3452-3459.

[28] A.M. Staiger, M. Ziepert, H. Horn, D.W. Scott, T.F.E. Barth, H.W. Bernd, A.C. Feller, W. Klapper, M. Szczepanowski, M. Hummel, H. Stein, D. Lenze, M.L. Hansmann, S. Hartmann, P. Moller, S. Cogliatti, G. Lenz, L. Trumper, M. Loffler, N. Schmitz, M. Pfreundschuh, A. Rosenwald, G. Ott and German High-Grade Lymphoma Study Group, Clinical Impact of the Cell-of-Origin Classification and the MYC/ BCL2 Dual Expresser Status in Diffuse Large BCell Lymphoma Treated within Prospective Clinical Trials of the German High-Grade NonHodgkin's Lymphoma Study Group, J.Clin.Oncol. 35 (2017), pp. 2515-2526.

[29] B. Coiffier, E. Lepage, J. Briere, R. Herbrecht, H. Tilly, R. Bouabdallah, P. Morel, E. Van Den Neste, G. Salles, P. Gaulard, F. Reyes, P. Lederlin and C. Gisselbrecht, CHOP Chemotherapy Plus Rituximab Compared with CHOP Alone in Elderly Patients with Diffuse Large-B-Cell Lymphoma, N.Engl.J.Med. 346 (2002), pp. 235-242.

[30] M. Pfreundschuh, J. Schubert, M. Ziepert, R. Schmits, M. Mohren, E. Lengfelder, M. Reiser, C. Nickenig, M. Clemens, N. Peter, C. Bokemeyer, H. Eimermacher, A. Ho, M. Hoffmann, R. Mertelsmann, L. Trumper, L. Balleisen, R. Liersch, B. Metzner, F. Hartmann, B. Glass, V. Poeschel, N. Schmitz, C. Ruebe, A.C. Feller, M. Loeffler and German High-Grade NonHodgkin Lymphoma Study Group (DSHNHL), Six Versus Eight Cycles of Bi-Weekly CHOP14 with Or without Rituximab in Elderly Patients with Aggressive CD20+ B-Cell Lymphomas: A Randomised Controlled Trial (RICOVER-60), Lancet Oncol. 9 (2008), pp. 105-116.

[31] M. Pfreundschuh, E. Kuhnt, L. Trumper, A. Osterborg, M. Trneny, L. Shepherd, D.S. Gill, J. Walewski, R. Pettengell, U. Jaeger, P.L. Zinzani, O. Shpilberg, S. Kvaloy, P. de Nully Brown, R. Stahel, N. Milpied, A. Lopez-Guillermo, V. Poeschel, S. Grass, M. Loeffler, N. Murawski and MabThera International Trial (MInT) Group, CHOP-Like Chemotherapy with Or without Rituximab in Young Patients with Good-Prognosis Diffuse Large-B-Cell Lymphoma: 6-Year Results of an Open-Label Randomised Study of the MabThera International Trial (MInT) Group, Lancet Oncol. 12 (2011), pp. 1013-1022.

[32] T.M. Habermann, E.A. Weller, V.A. Morrison, R.D. Gascoyne, P.A. Cassileth, J.B. Cohn, S.R. Dakhil, B. Woda, R.I. Fisher, B.A. Peterson and S.J. Horning, Rituximab-CHOP Versus CHOP Alone Or with Maintenance Rituximab in Older Patients with Diffuse Large B-Cell Lymphoma, J.Clin.Oncol. 24 (2006), pp. 3121-3127.

This article is protected by copyright. All rights reserved. 
[33] N. Schmitz, S. Zeynalova, M. Nickelsen, R. Kansara, D. Villa, L.H. Sehn, B. Glass, D.W. Scott, R.D. Gascoyne, J.M. Connors, M. Ziepert, M. Pfreundschuh, M. Loeffler and K.J. Savage, CNS International Prognostic Index: A Risk Model for CNS Relapse in Patients with Diffuse Large B-Cell Lymphoma Treated with R-CHOP, J.Clin.Oncol. 34 (2016), pp. 3150-3156.

This article is protected by copyright. All rights reserved. 


\section{Figure legends}

Figure 1. Kaplan-Meier survival analysis for the patients treated with CHOP-like chemotherapy with or without rituximab (R+/-), a) Progression free survival (PFS) b) Overall survival (OS) c) PFS for the patients less than 76 years $(<76 y)$ d) OS for the patients $<76 \mathrm{y}$.

Figure 2. Kaplan-Meier survival analysis for the patients treated with CHOP-like chemotherapy with or without CNS-directed therapy (CNS dir+/-), a) Progression free survival (PFS) b) Overall survival (OS) c) PFS for the patients less than 76 years ( $<76 \mathrm{y})$ d) OS for the patients $<76 \mathrm{y}$.

Figure 3. Kaplan-Meier survival analysis for the patients treated with CHOP-like chemotherapy with or without rituximab ( $\mathrm{R}+/-)$ and with or without CNS-directed chemotherapy (CNS dir+/-), a) Progression free survival (PFS) b) Overall survival (OS).

This article is protected by copyright. All rights reserved. 
Table 1. Patient demographics

\begin{tabular}{|c|c|c|c|c|c|c|}
\hline & All n (\%) & $R+$ & CNS dir+ & $<76 y n(\%)$ & $R+<76 y$ & $\begin{array}{l}\text { CNS dir }+ \\
<76 y\end{array}$ \\
\hline & $46(100)$ & 25 (100) & $24(100)$ & 40 (100) & $20(100)$ & $24(100)$ \\
\hline Male & $30(65)$ & $16(64)$ & $17(71)$ & $27(68)$ & $14(70)$ & $17(71)$ \\
\hline$\geq 60 y$ & $24(52)$ & $12(48)$ & $8(33)$ & $18(45)$ & $7(35)$ & $8(33)$ \\
\hline Stage I-II & $34(74)$ & $19(76)$ & $18(75)$ & $29(73)$ & $15(75)$ & $18(75)$ \\
\hline ECOG 0-1 & $41(89)$ & $24(96)$ & $21(88)$ & $35(88)$ & $19(95)$ & $21(88)$ \\
\hline LDH elevated & $\begin{array}{l}18(40) \\
\text { missing } 1(2)\end{array}$ & $8(32)$ & $\begin{array}{l}13(54), \\
\text { missing } 1 \\
(4)\end{array}$ & $\begin{array}{l}17(43) \\
\text { missing } 1(3)\end{array}$ & $7(35)$ & $\begin{array}{l}13(54), \\
\text { missing } 1 \\
(4)\end{array}$ \\
\hline Extranod $>1$ & $6(13)$ & $5(20)$ & $2(8)$ & $5(13)$ & $4(20)$ & $2(8)$ \\
\hline IPI 0-2 & $35(76)$ & $21(84)$ & $19(79)$ & $30(75)$ & $17(85)$ & $19(79)$ \\
\hline $\mathrm{R}+$ & $25(54)$ & $25(100)$ & $13(54)$ & $20(50)$ & $20(100)$ & $13(54)$ \\
\hline CNS dir+ & $24(52)$ & $13(52)$ & $24(100)$ & $24(60)$ & $13(65)$ & $24(100)$ \\
\hline RT & $18(39)$ & $5(20)$ & $9(38)$ & $14(35)$ & $2(10)$ & $9(38)$ \\
\hline Nasal cavity & $\begin{array}{l}18(39) \text {, } \\
\text { exact location } \\
\text { not definable } 2 \\
\text { (4) }\end{array}$ & $11(44)$ & $\begin{array}{l}9(38), \\
\text { exact } \\
\text { location not } \\
\text { definable } 2 \\
(8)\end{array}$ & $\begin{array}{l}15(38) \text {, } \\
\text { exact location } \\
\text { not definable } 2 \\
(5)\end{array}$ & $8(40)$ & $\begin{array}{l}9(38), \\
\text { exact } \\
\text { location } \\
\text { not } \\
\text { definable } \\
2(8)\end{array}$ \\
\hline Paranasal & $\begin{array}{l}15(34) \text {, } \\
\text { exact location } \\
\text { not definable } 2 \\
\text { (4) }\end{array}$ & $10(40)$ & $\begin{array}{l}12(50), \\
\text { exact } \\
\text { location not } \\
\text { definable } \\
2(8)\end{array}$ & $\begin{array}{l}13(33) \text {, exact } \\
\text { location not } \\
\text { definable } \\
2(5)\end{array}$ & $9(45)$ & $\begin{array}{l}12(50), \\
\text { exact } \\
\text { location } \\
\text { not } \\
\text { definable } \\
2(8)\end{array}$ \\
\hline Nasopharyngeal & $\begin{array}{l}23(52) \text {, } \\
\text { exact location } \\
\text { not definable } 2 \\
\text { (4) }\end{array}$ & $11(44)$ & $\begin{array}{l}11(46), \\
\text { exact } \\
\text { location not } \\
\text { definable } \\
2(8)\end{array}$ & $\begin{array}{l}22(55), \\
\text { exact location } \\
\text { not definable } 2 \\
\text { (5) }\end{array}$ & $10(50)$ & $\begin{array}{l}11(46), \\
\text { exact } \\
\text { location } \\
\text { not } \\
\text { definable } \\
2(8)\end{array}$ \\
\hline
\end{tabular}

This article is protected by copyright. All rights reserved. 
$<76$ y, less than 76 years; $\geq 60$ y, patients 60 years or more; ECOG, Eastern Cooperative Oncology Group performance status; LDH, lactate dehydrogenase level; Extranod $>1$, more than one extranodal location; IPI, International Prognostic Index; R, rituximab; RT, radiotherapy; CNS dir, CNS-directed treatment

This article is protected by copyright. All rights reserved. 
Table 2. Treatment characteristics

$\begin{array}{llll}\text { Regimen } & \text { All } & \text { iv CNS dir+ } & \text { it CNS dir+ } \\ & \mathbf{n = 4 6} & \mathbf{n = 2 2} & \mathbf{n = 8} \\ \text { R-CHOP } & 24 & 12 & 4 \\ \text { M-BACOD/M-BAIOD } & 6 & 6 & 1 \\ \text { CHOP } & 8 & 0 & 1 \\ \text { Magrath (includes HD-MTX) [24] } & 1 & 1 & 1 \\ \text { CNOP } & 1 & 0 & 0 \\ \text { BLEO-CHOP + M-BACOD } & 1 & 1 & 0 \\ \text { COP } & 2 & 0 & 0 \\ \text { DA-EPOCH-R } & 1 & 0 & 1 \\ \text { CHOP + BACOD + HD-cytarabine } & 1 & 1 & 0 \\ \text { CHOP + M-BACOD } & 1 & 1 & 0\end{array}$

Used (immuno)chemotherapy combinations: CNS dir, CNS-directed chemotherapy; R, rituximab; CHOP, cyclophosphamide, doxorubicin, vincristine, prednisone; M-BACOD/M-BAIOD, methotrexate, bleomycin, doxorubicin, cyclophosphamide, ifosfamide, vincristine, dexamethasone; CNOP, cyclophosphamide, mitoxantrone, vincristine, prednisone; BLEO, bleomycin; DA-EPOCH-R, dose-adjusted, etoposide, prednisone, vincristine, cyclophosphamide, doxorubicin, rituximab; MTX, methotrexate. Some patients received CNS-directed chemotherapy both iv and it and are therefore listed in both groups.

This article is protected by copyright. All rights reserved. 
Table 3. Immunophenotype according to tumor location.

$\begin{array}{llllllll}\text { GCB } & \text { BCL2+ } & \text { BCL6+ } & \text { CD10+ } & \text { MUM1+ } & \text { MYC+ } & \text { Double } & \text { Triple } \\ \mathrm{n}=44 & \mathrm{n}=47(\%) & \mathrm{n}=45(\%) & \mathrm{n}=45 & \mathrm{n}=42(\%) & \mathrm{n}=24(\%) & \text { expressor } & \text { expressor } \\ (\%) & & & (\%) & & & \mathrm{n}=24(\%) & \mathrm{n}=24(\%)\end{array}$

$\begin{array}{llllllll}\text { All } & 14(32) & 41(87) & 39(87) & 11(24) & 35(83) & 16(67) & 15(63)\end{array}$

$\begin{array}{llllllll}\text { Nasal } & 4(27) & 15(88) & 13(81) & 4(27) & 12(80) & 3(38) & 3(38)\end{array}$

cavity

$\begin{array}{llllllll}\text { Paranasal } & 7(47) & 13(81) & 12(86) & 3(19) & 9(64) & 2(33) & 2(33)\end{array}$

sinuses

$\begin{array}{llllllll}\text { Nasophar } & 8(36) & 21(88) & 20(83) & 7(29) & 17(85) & 10(77) & 10(77)\end{array}$

ynx



location

not

definable

Double expressor, tumour positive for MYC and BCL2 or BCL6 in immunohistochemistry; Triple expressor, tumour positive for MYC and BCL2 and BCL6 in immunohistochemistry

This article is protected by copyright. All rights reserved. 
A

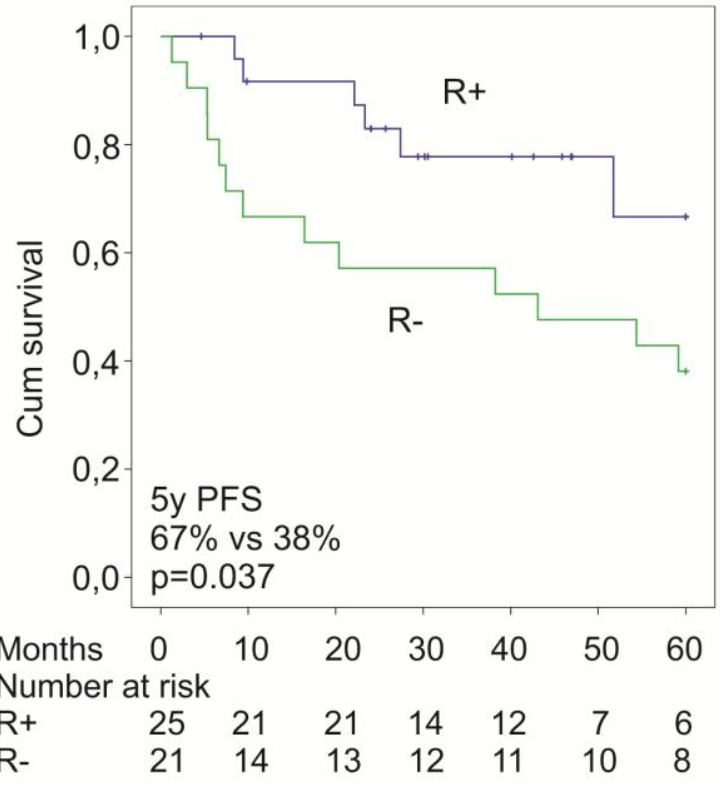

C

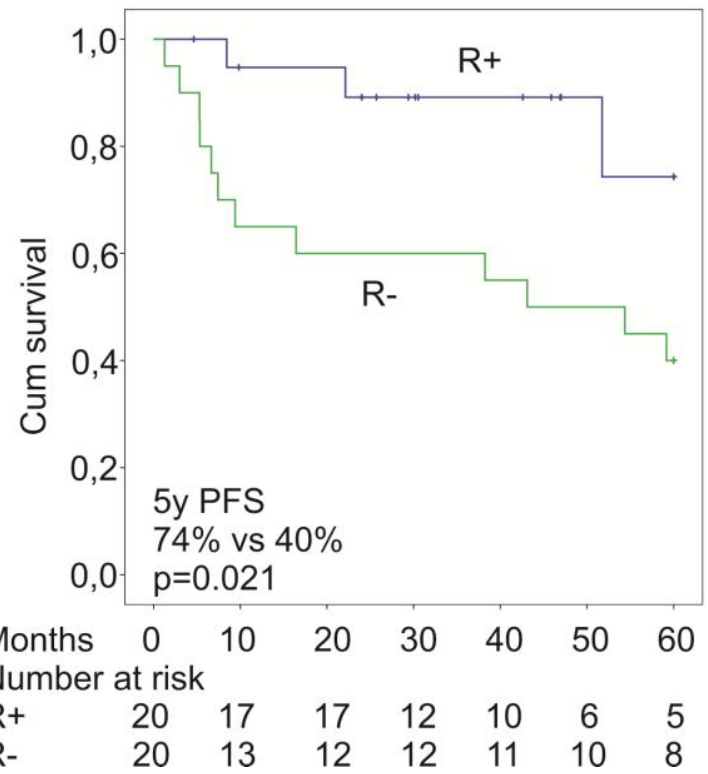

B

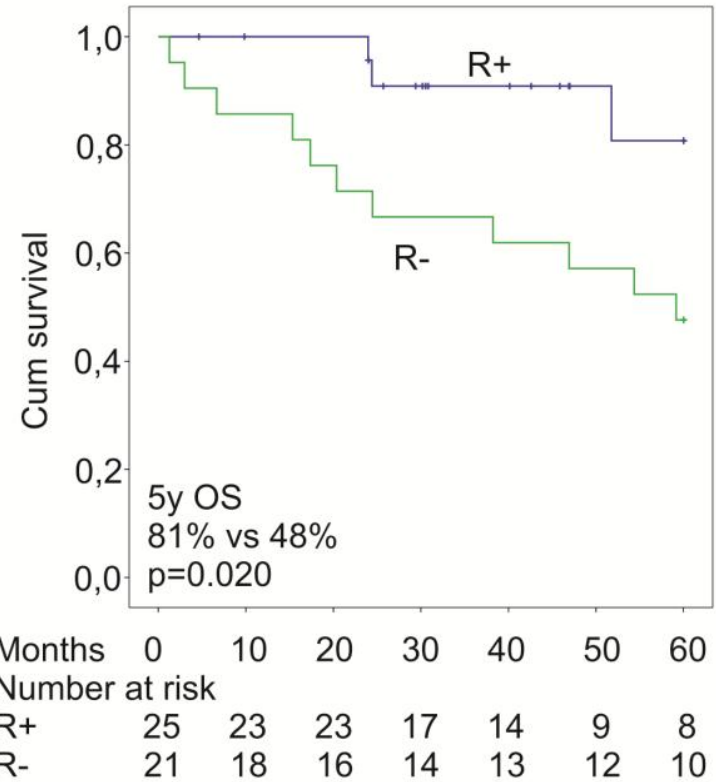

$\begin{array}{llllllcc}\mathrm{R}+ & 25 & 23 & 23 & 17 & 14 & 9 & 8 \\ \mathrm{R}- & 21 & 18 & 16 & 14 & 13 & 12 & 10\end{array}$

D

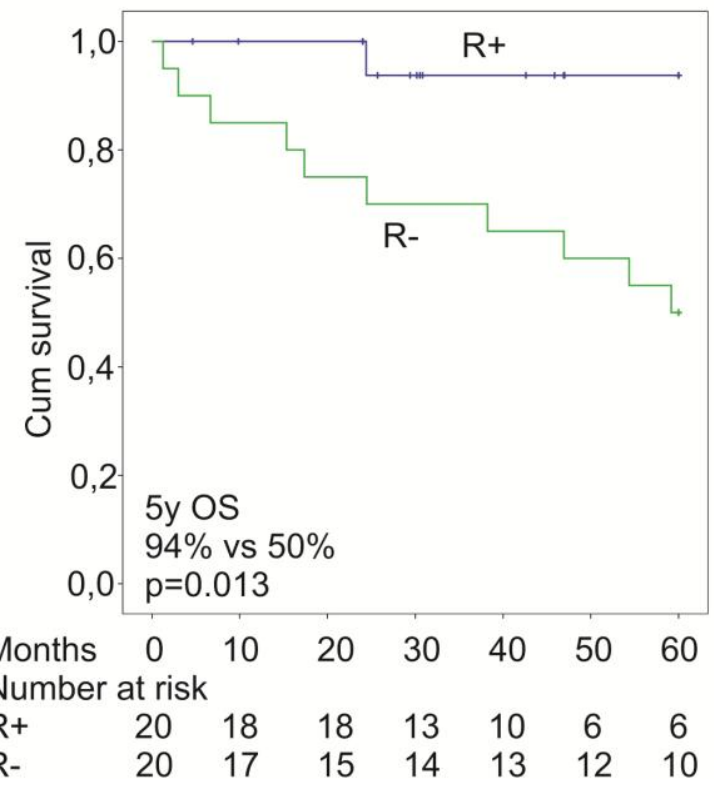

This article is protected by copyright. All rights reserved. 

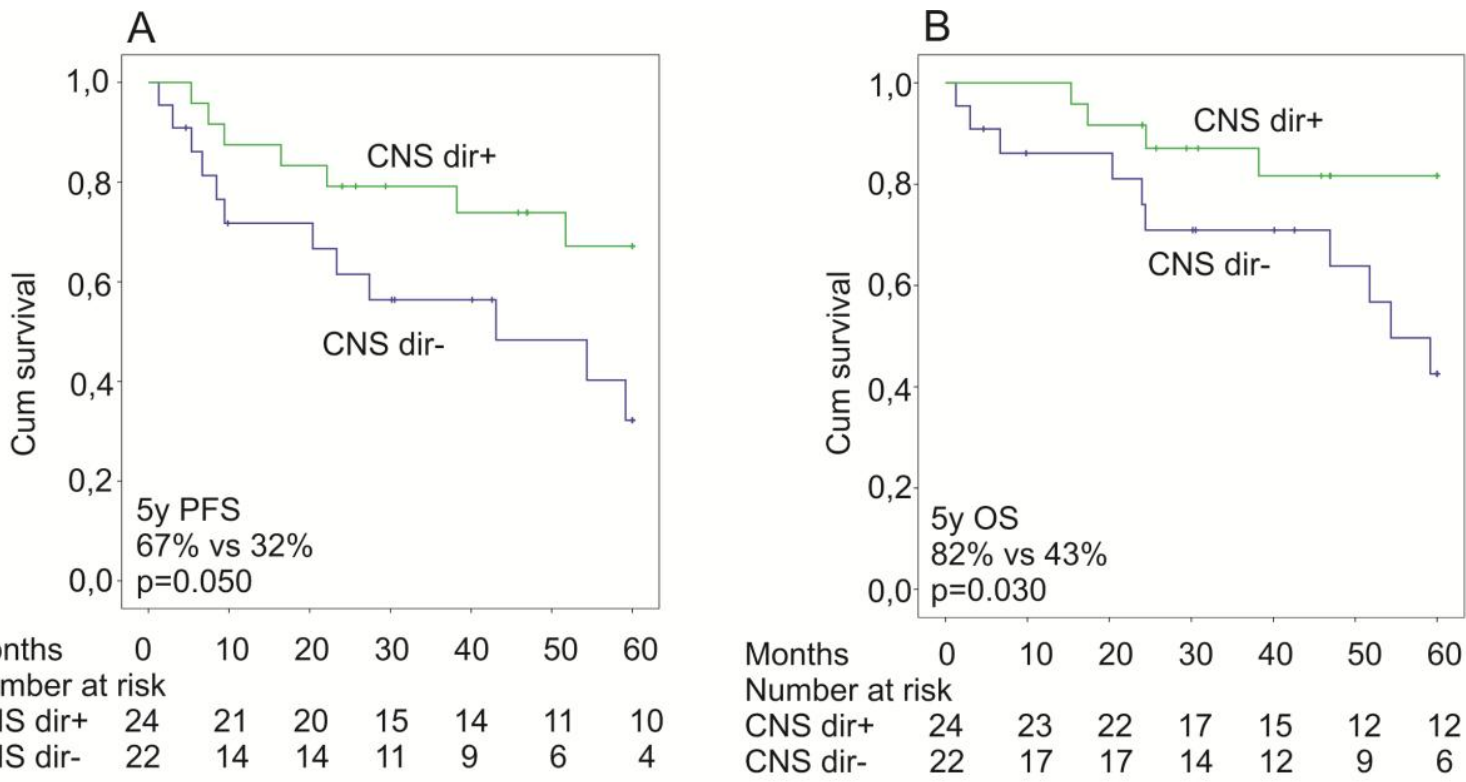

C
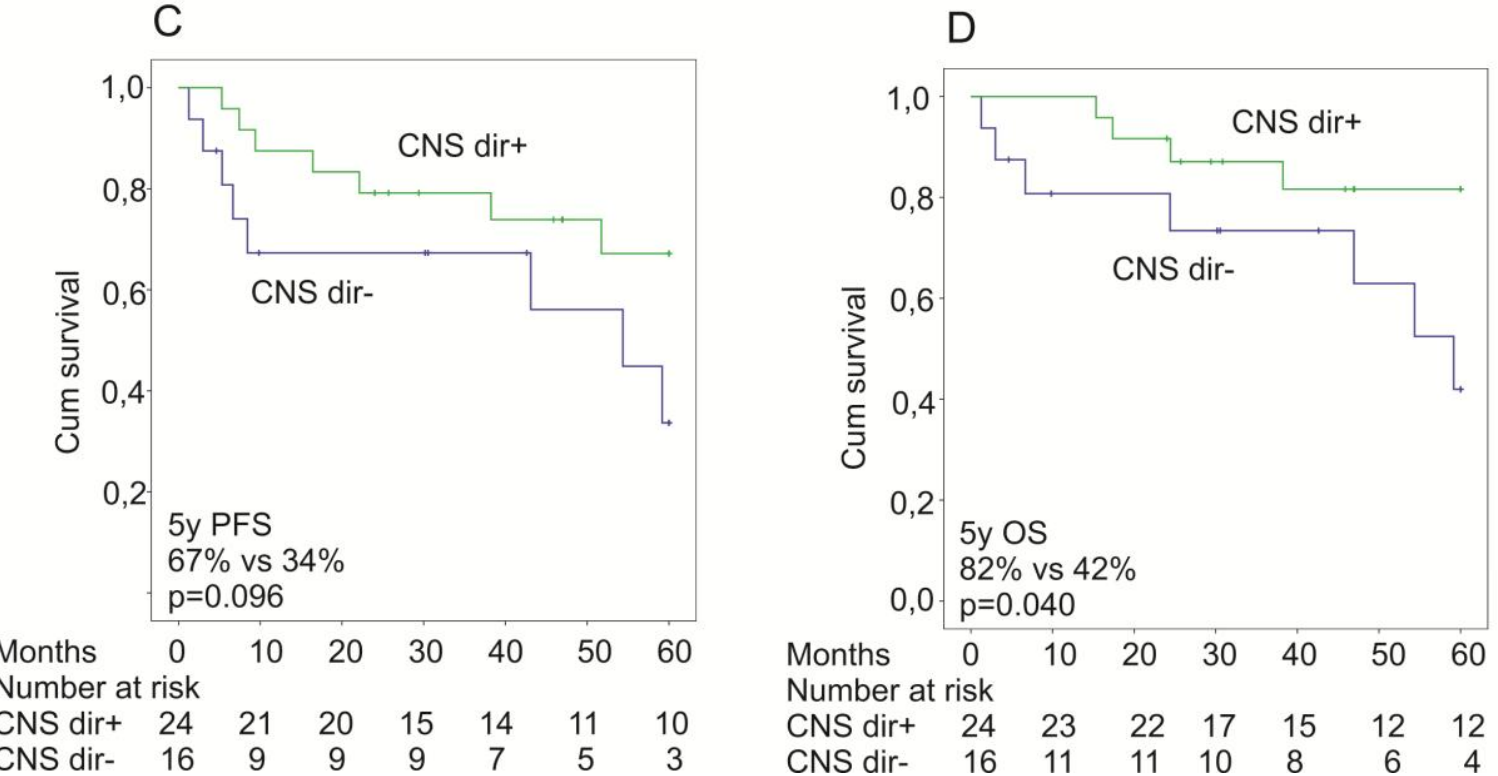

This article is protected by copyright. All rights reserved. 


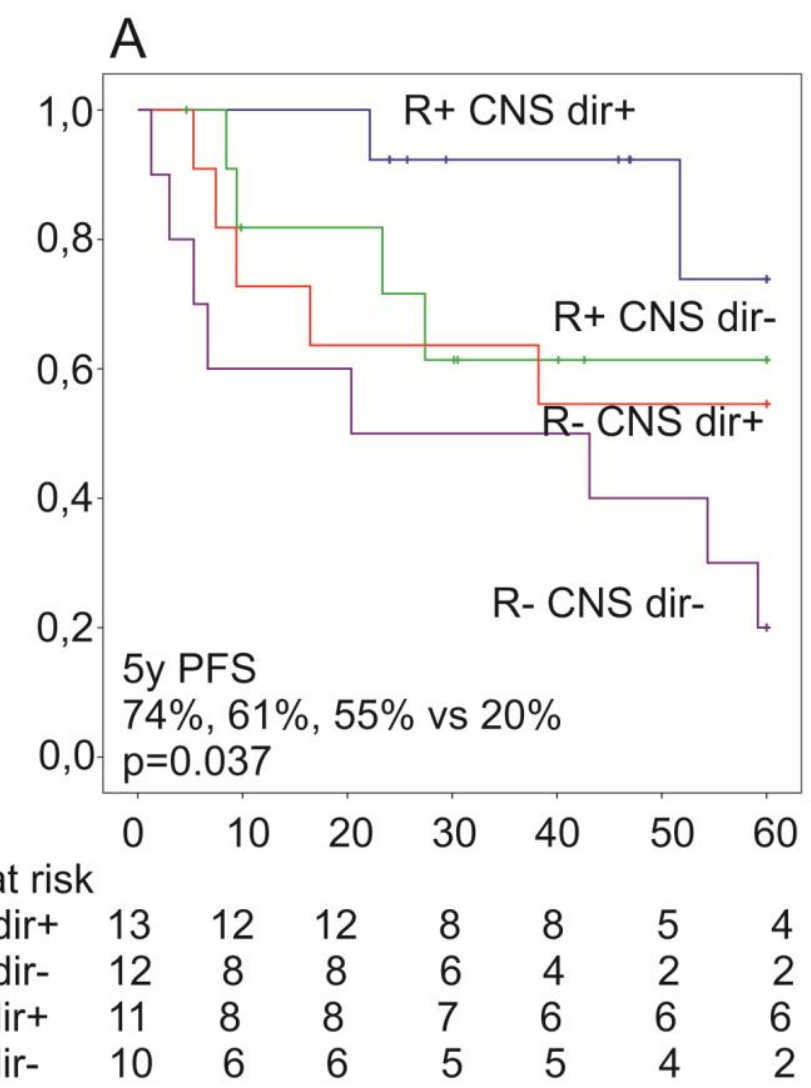

B

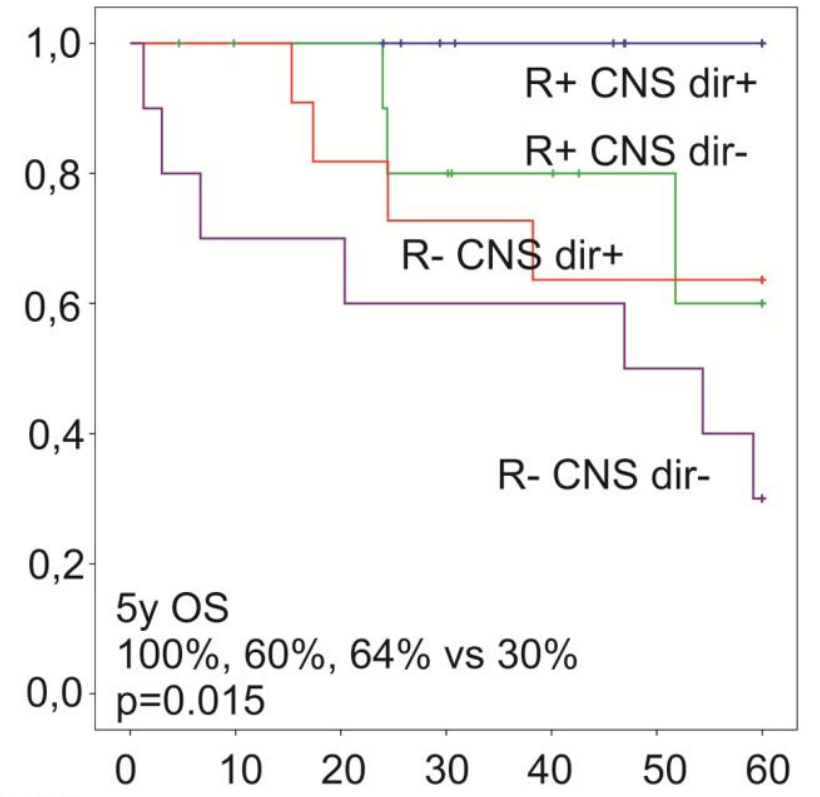

Months

Number at risk

$\begin{array}{llllllll}\mathrm{R}+\mathrm{CNS} \text { dirt } & 13 & 12 & 12 & 9 & 8 & 5 & 5\end{array}$

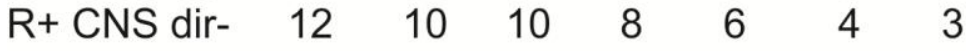

$\begin{array}{llllllll}\text { R- CNS dirt } & 11 & 10 & 9 & 8 & 7 & 7 & 7\end{array}$

$\begin{array}{llllllll}\text { R- CNS dir- } & 10 & 7 & 7 & 6 & 6 & 5 & 3\end{array}$

This article is protected by copyright. All rights reserved. 